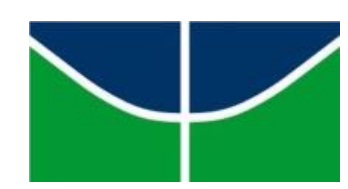

UNIVERSIDADE DE BRASÍLIA

FACULDADE DE CIÊNCIAS DA SAÚDE

DEPARTAMENTO DE ENFERMAGEM

MARIANA TERRA ALVES DE OLIVEIRA

"AS REPERCUSSÕES DO CÂNCER DA CRIANÇA NAS RELAÇÕES FAMILIARES: REVISÃO INTEGRATIVA DA LITERATURA NACIONAL"

BRASÍLIA

2018 


\section{“AS REPERCUSSÕES DO CÂNCER DA CRIANÇA NAS RELAÇÕES FAMILIARES"}

Trabalho de Conclusão de Curso apresentado ao Departamento de Enfermagem da Faculdade de Ciências da Saúde, campus Darcy Ribeiro, Universidade de Brasília para a obtenção do grau de Bacharel em Enfermagem Aluna: Mariana Terra Alves de Oliveira. Área de Concentração: Cuidado da Criança e do Adolescente.

Linha de Pesquisa: Família, Criança e Cuidado: estudo das experiências nas transições de saúde e doença.

Orientadora: Profa. Dra. Aline Oliveira Silveira 


\title{
“ AS REPERCUSSÕES DO CÂNCER DA CRIANÇA NAS RELAÇÕES
} FAMILIARES: REVISÃO INTEGRATIVA NACIONAL"

\author{
Trabalho de Conclusão de Curso apresentado ao \\ Departamento de Enfermagem da Faculdade de \\ Ciências da Saúde, campus Darcy Ribeiro, \\ Universidade de Brasília para a obtenção do grau de \\ Bacharel em Enfermagem Aluna: Mariana Terra \\ Alves de Oliveira.
}

Aprovado em:

BANCA EXAMINADORA

Profa. Ma. Mariana André Honorato Franzoi

Profa. Dra. Rita de Cássia Melão de Morais

Profa. Dra. Gisele Martins 


\section{DEDICATÓRIA}

Dedico este trabalho as famílias de crianças com câncer que tem tanta perseverança, aos profissionais que trabalham na oncologia e lidam com as famílias constantemente, ao meu avô que também tinha uma condição crônica e não pôde me acompanhar até o final, aos meus amigos, familiares e orientadora que me apoiaram durante a trajetória. 


\section{AGRADECIMENTOS}

Agradeço primeiramente a Deus pela oportunidade de percorrer toda essa trajetória desde o início da graduação, pela oportunidade também de realizar a graduação e este trabalho na Universidade de Brasília.

Agradeço imensamente a minha família, a minha orientadora profa. Dra. Aline Oliveira Silveira por ter me apoiado em todos os momentos e aos meus amigos que me apoiaram a cada semestre durante todos esses anos de convivência na Universidade. 


\section{SUMÁRIO}

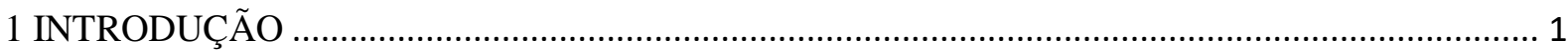

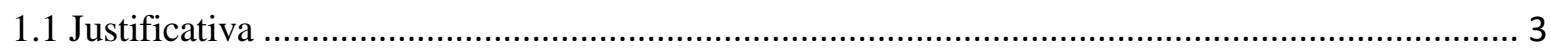

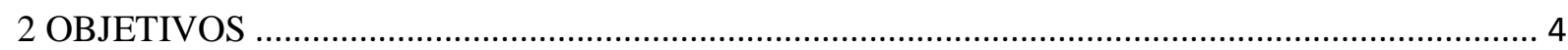

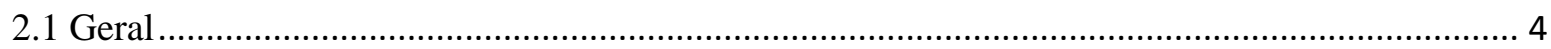

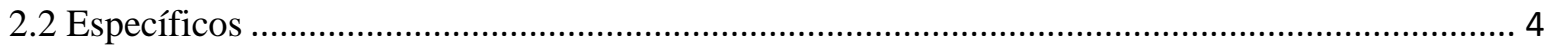

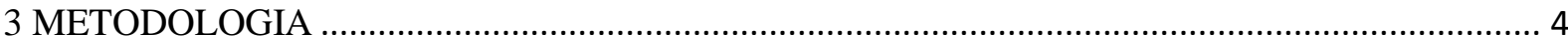

3.2 BUSCA E SELEÇÃO DOS ESTUDOS ………………………………………………….... 5

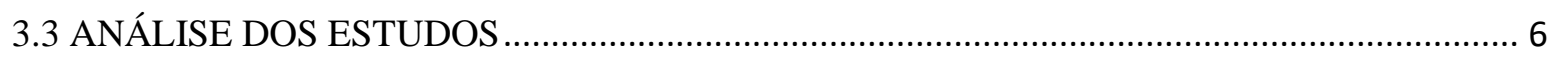

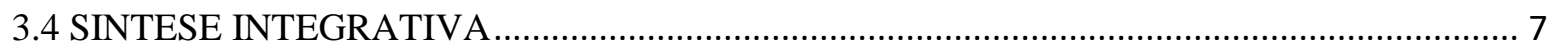

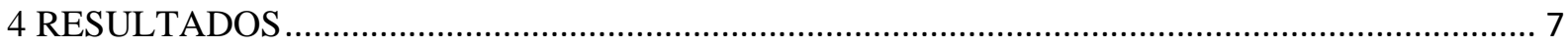

4.1 Mudanças Estruturais .............................................................................................. 13

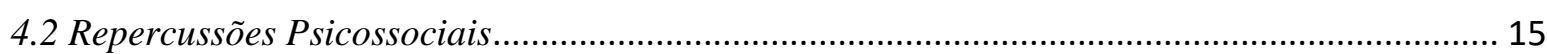

4.3 Mudanças nos Padrões de Comunicação e Relacionamento Familiar...................................... 17

4.4 A relação entre a equipe de saúde e a família …………………............................................. 19

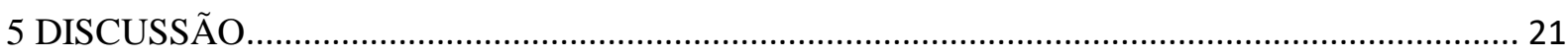

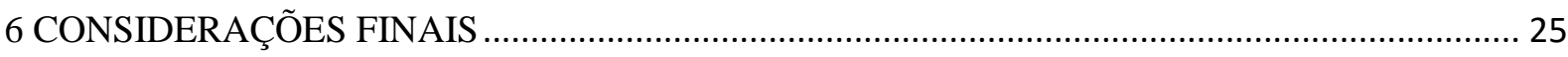

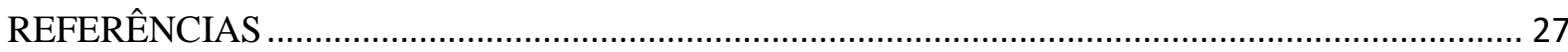




\section{RESUMO}

O câncer infantil é uma doença que tem apresentado um aumento na taxa de incidência no Brasil e que traz modificações nas relações familiares com importantes repercussões físicas, emocionais, psicossociais e financeiras, demandando novas formas de organização enfrentamento e adaptação da família. Nesse contexto a família vivencia sofrimentos e incertezas e utiliza diferenciadas estratégias de manejo. Assim, a pesquisa teve como objetivo geral: realizar uma revisão integrativa da literatura sobre as repercussões do câncer infantil nas relações familiares, descrevendo as principais mudanças na dinâmica familiar e as estratégias de manejo desenvolvidas pela família na vivência do câncer da criança. Metodologia: Revisão Integrativa da Literatura a partir da questão norteadora: quais as repercussões do câncer infantil nas relações familiares? A busca foi realizada nas bases de dados LILACS (Literatura Latino-americana e do Caribe em Ciências da Saúde), SciELO (Scientific Eletronic Library Online), Portal de periódicos da CAPES e Banco de teses e dissertações da CAPES. Foram utilizados os descritores: neoplasia, criança, relações familiares, impacto psicossocial e relações familiares e as expressões: família, câncer e câncer infantil de forma combinada. Os limites de busca foram estudos nacionais publicados nos últimos 5 anos (2013 a 2017) que tivessem como foco o câncer infantil e as relações familiares. A análise consistiu na integração dos resultados das pesquisas primárias por meio de categorização dos dados, considerando-se as similaridades e complementaridades conceituais. Resultados: A amostra final foi composta por 25 estudos, os quais demonstraram as modificações familiares decorrentes do câncer da criança implicando em alterações na dinâmica familiar, na estrutura, comunicação, relacionamentos e nas suas redes sociais. A análise integrativa permitiu a identificação de 4 categorias temáticas: mudanças estruturais, repercussões psicossociais, mudanças nos padrões de comunicação e relacionamento familiar e a relação entre equipe de saúde e família. Conclusão: A síntese integrativa permitiu compreender de forma mais ampla e aprofundada a dimensão das repercussões do câncer da criança nas relações familiares fornecendo evidências e estratégias para o cuidado de enfermagem centrado na criança e na família considerando a especificidade da situação de vivenciar o câncer infantil na vivencia e qualidade de vida familiar.

Descritores: neoplasias, criança, relações familiares, impacto psicossocial, enfermagem familiar. 


\begin{abstract}
Childhood cancer is a disease that has shown an increase in the incidence rate in Brazil and that brings about changes in family relations with important physical, emotional, psychosocial and financial repercussions, demanding new forms of organization coping and adaptation of the family. In this context the family experiences sufferings and uncertainties and uses different management strategies. Thus, the research had as its general objective: to carry out an integrative review of the literature on the repercussions of childhood cancer in family relationships, describing the main changes in family dynamics and management strategies developed by the family in the child's cancer experience. Methodology: Integrative Review of Literature from the guiding question: what are the repercussions of childhood cancer in family relationships? The search was carried out in the LILACS (Latin American and Caribbean Literature in Health Sciences), SciELO (Scientific Electronic Library Online), CAPES Journal Portal and CAPES Thesis and Dissertation Bank. The descriptors were: neoplasia, child, family relationships, psychosocial impact and family relations and the expressions: family, cancer and childhood cancer combined. The search limits were national studies published in the last 5 years (2013 to 2017) that focused on childhood cancer and family relationships. The analysis consisted of integrating the results of the primary research through categorization of the data, considering the similarities and conceptual complementarities. Results: The final sample consisted of 25 studies, which demonstrated the family changes due to the child's cancer, implying changes in family dynamics, structure, communication, relationships and in their social networks. Integrative analysis allowed the identification of four thematic categories: structural changes, psychosocial repercussions, repercussions on communication patterns and family relationships, and the relationship between the health team and the family. Conclusion: Integrative synthesis allowed a broader and more thorough understanding of the dimension of the child's cancer repercussions in family relationships, providing evidence and strategies for child and family centered nursing care considering the specificity of the situation of experiencing childhood cancer in the experience and quality of family life.
\end{abstract}

Keywords: neoplasms, child, family relationships, psychosocial impact, family nursing. 


\section{LISTA DE FIGURAS}

Figura 1 - Processo de seleção dos estudos ------------------------------ 6 


\section{LISTA DE TABELAS}

Tabela 1 - Caracterização das pesquisas inclusas na revisão integrativa ----------------7

Tabela 1 - Caracterização das pesquisas inclusas na revisão integrativa ----------------8

Tabela 1 - Caracterização das pesquisas inclusas na revisão integrativa ---------------9

Tabela 1 - Caracterização das pesquisas inclusas na revisão integrativa ---------------10

Tabela 1 - Caracterização das pesquisas inclusas na revisão integrativa --------------11

Tabela 1 - Caracterização das pesquisas inclusas na revisão integrativa --------------12 


\section{INTRODUÇÃO}

O câncer infantil é uma doença na qual ocorre a proliferação descontrolada de células anormais e pode surgir em qualquer parte do organismo, são neoplasias malignas que podem atingir crianças de até 15 anos. Os tumores mais presentes na infância são as leucemias, seguido pelos tumores de sistema nervoso central (SNC) e linfomas. (INCA/MS; 2017).

A classificação dos tumores da criança é realizada com base na morfologia de acordo com a Classificação Internacional de Doenças para Oncologia (CID-O). As edições são atualizadas, tendo atualmente o (CID-O3), que introduziu códigos de morfologia para leucemias e linfomas, para agrupar tais códigos foi realizada a CICI-3 (Classificação Internacional do Câncer na Infância). (STELIAROVA-FOUCHER, 2009).

A classificação da CICI-3 divide os tumores da infância em I- Leucemias, doença mieloproliferativa e doenças mioleoplásica; II- Linfomas e neoplasias do sistema reticuloendotelial; III- Tumores do sistema nervoso central e miscelânea dos tumores intracranianos e intraespinais; IV- Neuroblastoma e tumores de células nervosas periféricas; V-Retinoblastoma. VI- Tumores renais; VII- Tumores hepáticos; VIII- Tumores ósseos malignos; IX- Sarcomas de partes moles e extra ósseos; X- Tumores de células germinativas, tumores trofoblásticos e neoplasias de gônodas; XI- Outras neoplasias malignas epiteliais e melanoma maligno. (STELIAROVA-FOUCHER, 2009).

O câncer apresenta a primeira causa de morte por doenças em crianças e adolescentes entre 1 e 19 anos de idade no Brasil, e também há predomínio das leucemias como tumor mais frequente na infância, com média de $29 \%$. Sendo que, para as leucemias a maior incidência ocorre entre 1 e 4 anos com média de 31,6\%. (INCA, 2017).

Os números de neoplasias no Brasil em crianças de 0 a 19 anos de idade, são divididos de acordo com as regiões. Na região Norte o total de neoplasias vai de 1.019 a 8.735 ; na região Nordeste de 2.250 a 19.767 ; na região Centro-Oeste de 3.873 a 16.530; na região Sudeste de 1.941 a 160.560 e na região Sul de 4.725 a 26.025 neoplasias. (INCA/MS; 2017).

No Brasil, as neoplasias são causa de mortalidade de $30 \%$ a $40 \%$ de crianças com câncer na idade de 0 anos; de $44 \%$ a $52 \%$ em crianças de 1 a 4 anos; de $33 \%$ a $42 \%$ em crianças de 5 a 9 anos; de $35 \%$ a $42 \%$ de crianças 10 a 14 anos e de $43 \%$ a $64 \%$ de crianças de 15-19 anos de 2009 a 2013. (INCA/MS; 2017).

A estrutura familiar é o conjunto de relações entre quem compõem a família e da família com os demais sistemas sociais. Os padrões de organização da família tendem a se estabilizar ao longo do tempo. As regras e normas das relações familiares não são claramente 
definidas pela cultura, essas regras vão evoluindo conforme as interações dentro da família vão ocorrendo (BALLARD; 2005).

O câncer infantil traz importantes repercussões, sentimentos negativos e sofrimento familiar, principalmente medo da perda da criança ao receber o diagnóstico e entrar num mundo de incertezas e de estigmas relacionados ao câncer. (BARRETO; 2014).

As mães que sobrevivem ao câncer infantil ainda possuem sentimentos de medo e ansiedade pela possibilidade do retorno da doença e das suas consequências mesmo após a cura, e acabam desenvolvendo sintomas de transtorno pós-traumático demonstrando as repercussões psicológicas e vulnerabilidade das famílias diante do adoecimento da criança (LAWRENZ, PEUKER,CASTRO; 2016).

O sentimento de culpa é intensamente vivido pela família que revê seus comportamentos na tentativa de compreender e identificar quais comportamentos levaram ao adoecimento da criança, além dos sentimentos de impotência e fracasso por não ter conseguido proteger o filho (DIAS; 2016).

O afastamento de um membro familiar é uma situação comum, devido as necessidades de cuidados e hospitalizações frequentes, que levam a família, a deixar o emprego em prol do cuidado exclusivo da criança, principalmente a mãe, figura que também que se torna a principal responsável por tal acompanhamento (BARRETO; 2014). Além de lidar com a doença, as famílias tem que cuidar do lar e dos outros membros familiares (LAWRENZA, PEUKER, CASTRO; 2016) e dessa forma o pai acaba ficando como provedor do lar e responsável pelo cuidado dos demais membros familiares (DIAS; 2016).

A família passa por muitos rearranjos para lidar com o adoecimento do filho e se reorganiza para cuidar da criança com câncer, passando por problemas financeiros, mudanças de rotina, sociais e de relacionamento. (BARRETO; 2014). A maior parte das famílias tem a necessidade de se mudar do seu lar ou de deslocamentos constantes aos grandes centros em que se encontram os centros de oncologia pediátrica e intenso gasto financeiro com exames, medicações e a própria condição da criança, sendo um dos fatores de vulnerabilidade e sobrecarga para as famílias (MARQUES; 2017).

O afastamento do lar, das atividades diárias e da vida social da família para acompanhar a criança com câncer é um fator contribuinte para o desenvolvimento de problemas psicológicos nessas famílias, como angústia, ansiedade e depressão, o que também geram outra demanda de cuidados específicos voltados para a família (DIAS; 2016). 
Apesar do intenso sofrimento as famílias mantém a esperança na cura da criança e transmite-as para a criança para que esta continue aderindo ao tratamento, a não ser nos casos de aproximação real da morte em que a família inicia o processo de luto antes mesmo da morte da criança (DIAS; 2016).

O suporte social é uma importante forma de enfrentamento manejada pelas famílias de crianças com câncer, nesse contexto o enfermeiro é um profissional que deve ser capaz de funcionar como um dos sistemas de apoio, buscando redes sociais distintas de forma a minimizar tais impactos sobre a família (MARQUES; 2017).

O câncer infantil tem repercussões físicas, psicológicas, emocionais e sociais importantes na dinâmica familiar. A família modifica suas relações, atividades diárias e rotina, alterando a sociabilidade, comunicação familiar e com a criança, buscando sempre levar esperança e apoio ao filho. Nesse contexto a enfermagem possui o importante papel de compreender tais modificações nas relações familiares para o desenvolvimento de um plano de cuidados centrado na criança e sua família baseado em suas necessidades e apoiando-a no manejo e ajustamento. Assim, tem-se como questionamento: Quais as repercussões do diagnóstico do câncer infantil nas relações familiares?

\subsection{Justificativa}

Sabe-se que o câncer na infância é uma doença com aumento progressivo na taxa de incidência e que provoca mudanças importantes na vida da criança e da família, com repercussões nas dimensões física, social, espiritual, econômica, emocional e psicoafetiva.

A revisão integrativa da literatura foi a metodologia utilizada neste trabalho por auxiliar na construção de conhecimentos sobre as mudanças geradas a partir do diagnóstico do câncer na criança demandam da família novas formas de organização e interação para enfrentarem os desafios impostos e adaptarem-se às novas circunstâncias de vida, bem como as estratégias de manejo desenvolvidas e as repercussões nas relações familiares e as implicações para a prática clínica de enfermagem.

As alterações na vida familiar geram mudanças importantes na organização familiar, são muitas modificações nas relações familiares e as famílias possuem estratégias distintas de enfrentamento, apesar de existirem alguns estudos na área, é um campo vasto de conhecimento e porém alguns subtemas como a recidiva do câncer na infância e a relação do pai em tal cuidado ainda existem poucos estudos. Dessa forma, a pesquisa justifica-se pela necessidade de compreender melhor as tais modificações na dinâmica familiar e os tipos de 
enfrentamento na vivência do câncer infantil para desenvolvimento de melhores estratégias de manejo da família e suas implicações para o cuidado de enfermagem. Nesse contexto a revisão integrativa contribui para o cuidado de enfermagem permitindo que este seja baseado em evidência, facilitando a incorporação dos conceitos e utilização na prática do cuidado. (MENDES, SILVEIRA, GALVÃO; 2008), portanto a família pode elaborar uma melhor gestão e enfrentamento dos estressores e modificações advindos com a da doença da criança e dos aspectos associados a ela, auxiliados pela equipe de enfermagem.

\section{OBJETIVOS}

\subsection{Geral}

- Realizar uma revisão integrativa da literatura sobre as repercussões do câncer da criança nas relações familiares.

\subsection{Específicos}

- Descrever as principais mudanças na dinâmica familiar após o diagnóstico do câncer da criança;

- Descrever e analisar as estratégias desenvolvidas pela família para manejar as mudanças geradas na vivência do câncer da criança.

\section{METODOLOGIA}

Estudo de revisão integrativa da literatura. A revisão integrativa busca elaborar um arcabouço de conhecimentos sobre um tema específico por meio de levantamento de dados, análise e síntese de diversos estudos como resultados pensando pesquisas futuras e a prática clínica (SOUZA, SILVA, CARVALHO; 2010). Foram utilizadas as etapas de identificação da hipótese, busca na literatura, categorização dos resultados, avaliação dos resultados, interpretação dos resultados e apresentação da síntese do conhecimento (MENDES, SILVEIRA, GALVÃO; 2008).

A questão norteadora adotada para o estudo foi: Quais as repercussões do câncer infantil nas relações familiares? 


\subsection{BUSCA E SELEÇÃO DOS ESTUDOS}

Os dados foram coletados de dezembro de 2017 a fevereiro de 2018 nas bases de dados LILACS (Literatura Latino-Americana e do Caribe em Ciências da Saúde), SciELO, Portal de periódicos da CAPES e Banco de teses e dissertações da CAPES disponíveis pela Universidade de Brasília. Como estratégia de busca foram utilizados os descritores contidos no DeCS (Descritores em ciências da Saúde): neoplasias, crianças, relações familiares, impacto psicossocial e enfermagem familiar e as expressões: família, câncer e câncer infantil. Os operadores boleanos utilizados foram: OR e AND. Os descritores foram combinados em: câncer AND família, câncer infantil AND relações familiares, crianças AND câncer OR neoplasia AND relações familiares, câncer infantil AND família e criança AND câncer AND família.

Os critérios de inclusão foram: estudos nacionais escritos em português dos últimos 5 anos (entre 2013 e 2017) devido a quantidade de artigos mais antigos quanto a temática, que apresentassem como objeto de estudo o câncer infantil e suas repercussões nas relações familiares. Os critérios de exclusão foram qualquer estudo que não abarcasse a temática, que não fosse nacional ou não estivesse escrito em português, que falasse sobre percepção profissional, repetidos ou que não continha o texto na íntegra. O processo de seleção está representado no fluxograma na figura 1. 
Figura 1 - Processo de seleção dos estudos

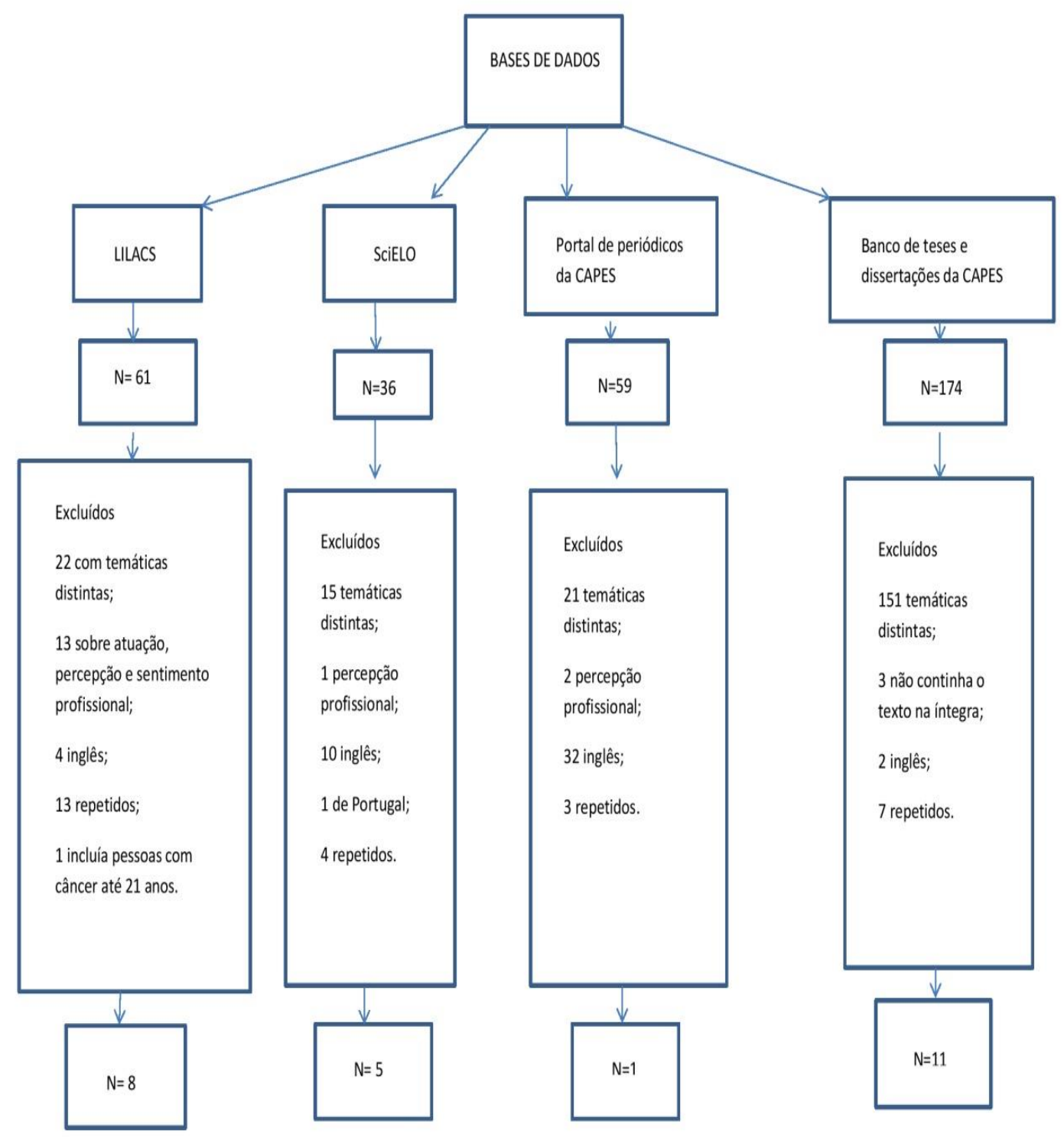

\subsection{ANÁLISE DOS ESTUDOS}

Os estudos foram selecionados primeiramente pelo título, depois pelo resumo e então procedeu-se a leitura na íntegra e a coleta dos dados relevantes foi realizada por meio de um instrumento com ênfase nas seguintes informações: autor, ano, sujeitos de pesquisa, metodologia, principais resultados e implicações para pesquisas futuras e para a prática clínica.

Para a análise crítica dos 25 estudos selecionados, aplicou-se o COREQ (Consolidated criteria for reporting qualitative research) que consiste em uma lista de checklist com 32 
itens que abordagem a confiabilidade das pesquisas qualitativas. (COSTA; 2016). Após esse processo foi realizada síntese integrativa.

\subsection{SINTESE INTEGRATIVA}

Os estudos foram analisados integralmente por leitura que direcionaram o agrupamento de dados e temas, depois foi realizada uma nova leitura que permitiu regularidades e similaridades presentes em cada tema para elaborar texto integrativo descritivo.

Esse processo permitiu a organização dos temas presentes nos resultados nas dimensões: estrutural (psicológicos, emocionais negativos e positivos, financeiros, sistemas de apoio, e vínculos formados), desenvolvimental (estratégias utilizadas pela família para se reorganizar, atividades diárias (modificações e novas atividades) e funcional (comunicação verbal e não-verbal família-criança, família e demais membros familiares, família-equipe de saúde/enfermagem, crenças, uniões e modificações na organização familiar).

A partir desses processos a síntese do conhecimento gerou 4 categorias temáticas: mudanças estruturais, repercussões psicossociais, repercussões nos padrões de comunicação e relacionamento familiar e a relação entre equipe de saúde e família.

\section{RESULTADOS}

A amostra final foi constituída por vinte e cinco estudos. Na análise dos 25 estudos constatou-se que 16 foram elaborados por pesquisadores na área de Enfermagem, sete na área de Psicologia e dois na área de Saúde Coletiva. No que se refere ao ano de publicação nove foram publicados no ano de 2013, seis no ano de 2014, cinco em 2015 e cinco em 2016. Quanto aos locais de realização da pesquisa sete foram realizados no estado de São Paulo, cinco na Paraíba, três no Rio Grande do Sul, dois em Minas Gerais, dois no Ceará, dois no Rio de Janeiro, um em Sergipe, um em Recife, um na Bahia e um em Manaus. Sendo que destes, 22 eram estudos originais e três revisões integrativas. A caracterização das pesquisas inclusas na revisão integrativa é apresentada na Tabela 1.

\begin{tabular}{|l|l|l|l|l|l|l|}
\hline \multicolumn{6}{|l|}{ Tabela 1 - Caracterização das pesquisas inclusas na revisão integrativa. } \\
\hline $\mathrm{N}^{\circ}$ & AUTOR & ANO & OBJETIVO & SUJEITO & LOCAL & METODOLOGIA \\
\hline 1 & $\begin{array}{l}\text { Maria } \\
\text { Noronha }\end{array}$ & 2013 & $\begin{array}{l}\text { Compreender } \\
\text { como os aspectos }\end{array}$ & & & $\begin{array}{l}\text { Revisão } \\
\text { Integrativa da }\end{array}$ \\
\hline
\end{tabular}




\begin{tabular}{|c|c|c|c|c|c|c|}
\hline & $\begin{array}{l}\text { Ferraz de } \\
\text { Arruda-Colli; } \\
\text { Manoel } \\
\text { Antônio dos } \\
\text { Santos. }\end{array}$ & & $\begin{array}{l}\text { psicológicos da } \\
\text { recidiva do câncer } \\
\text { infantil tem } \\
\text { surgido na } \\
\text { literatura } \\
\text { científica. }\end{array}$ & & & Literatura \\
\hline 2 & $\begin{array}{l}\text { Daniela } \\
\text { Doulavince } \\
\text { Amador; } \\
\text { Altamira } \\
\text { Pereira da } \\
\text { Silva } \\
\text { Reichert; } \\
\text { Regina } \\
\text { Aparecida } \\
\text { Garcia de } \\
\text { Lima; } \\
\text { Neusa Collet. }\end{array}$ & 2013 & $\begin{array}{l}\text { Analisar as } \\
\text { concepções de } \\
\text { cuidado e os } \\
\text { sentimentos que } \\
\text { permeiam o } \\
\text { cotidiano do } \\
\text { cuidador familiar } \\
\text { de crianças com } \\
\text { câncer. }\end{array}$ & $\begin{array}{l}9 \text { cuidadores } \\
\text { familiares de } \\
\text { crianças com } \\
\text { câncer de } 2 \text { a } 12 \\
\text { anos, sendo } 8 \text { mães } \\
\text { e } 1 \text { pai. }\end{array}$ & Paraíba & $\begin{array}{l}\text { Estudo } \\
\text { exploratório e } \\
\text { descritivo de } \\
\text { abordagem } \\
\text { qualitativa. }\end{array}$ \\
\hline 3 & $\begin{array}{l}\text { Mariana } \\
\text { Vendrami } \\
\text { Parra } \\
\text { Sanches; } \\
\text { Lucila } \\
\text { Castanheira } \\
\text { Nascimento; } \\
\text { Regina } \\
\text { Aparecida } \\
\text { Garcia de } \\
\text { Lima. } \\
\end{array}$ & 2013 & $\begin{array}{l}\text { Investigar a } \\
\text { experiência dos } \\
\text { familiares no } \\
\text { cuidar de crianças } \\
\text { e adolescentes } \\
\text { com câncer, em } \\
\text { cuidados } \\
\text { paliativos, } \\
\text { particularmente } \\
\text { nos cuidados ao } \\
\text { final da vida. }\end{array}$ & $\begin{array}{l}14 \text { familiares, } \\
\text { cuidadores de } \\
\text { crianças e } \\
\text { adolescentes que } \\
\text { morreram com } \\
\text { câncer. }\end{array}$ & São Paulo & $\begin{array}{l}\text { Estudo de } \\
\text { natureza } \\
\text { descritiva } \\
\text { exploratória com } \\
\text { análise qualitativa } \\
\text { dos dados. }\end{array}$ \\
\hline 4 & $\begin{array}{l}\text { Hilze Benigno } \\
\text { de Oliveira } \\
\text { Moura } \\
\text { Siqueira; } \\
\text { Manoel } \\
\text { Antônio dos } \\
\text { Santos; } \\
\text { Rodrigo } \\
\text { Ramon } \\
\text { Falconi } \\
\text { Gomez; } \\
\text { Simone } \\
\text { Saltareli; } \\
\text { Fátima } \\
\text { Aparecida } \\
\text { Emm Faleiros } \\
\text { Sousa. }\end{array}$ & 2015 & $\begin{array}{l}\text { Compreender a } \\
\text { experiência de dor } \\
\text { em crianças com } \\
\text { câncer. }\end{array}$ & $\begin{array}{l}17 \text { crianças } \\
\text { tratadas no serviço } \\
\text { de oncologia } \\
\text { pediátrica no } \\
\text { Hospital das } \\
\text { Clínicas de } \\
\text { Ribeirão Preto. }\end{array}$ & São Paulo & $\begin{array}{l}\text { Estudo } \\
\text { exploratório } \\
\text { descritivo } \\
\text { qualitativo. }\end{array}$ \\
\hline 5 & $\begin{array}{l}\text { Isabela Alves } \\
\text { Bernardes; } \\
\text { Renata } \\
\text { Fabiana } \\
\text { Pegoraro }\end{array}$ & 2015 & $\begin{array}{l}\text { Compreender de } \\
\text { que maneira } \\
\text { crianças saudáveis } \\
\text { lidam com a } \\
\text { notícia de } \\
\text { diagnóstico de } \\
\text { câncer e o } \\
\text { tratamento de um } \\
\text { de seus irmãos. }\end{array}$ & & & $\begin{array}{l}\text { Revisão } \\
\text { integrativa da } \\
\text { literatura. }\end{array}$ \\
\hline 6 & $\begin{array}{l}\text { Eduarda } \\
\text { Gayoso Meira }\end{array}$ & 2014 & $\begin{array}{l}\text { Investigar as } \\
\text { repercussões }\end{array}$ & $\begin{array}{l}11 \text { familiares que } \\
\text { estavam }\end{array}$ & Paraíba & $\begin{array}{l}\text { Estudo de campo } \\
\text { de abordagem }\end{array}$ \\
\hline
\end{tabular}




\begin{tabular}{|c|c|c|c|c|c|c|}
\hline & $\begin{array}{l}\text { Suassuna de } \\
\text { Medeiros; } \\
\text { Rosana Farias } \\
\text { Batista Leite; } \\
\text { Déborah } \\
\text { Karollyne } \\
\text { Ribeiro } \\
\text { Ramos; } \\
\text { Layze } \\
\text { Amanda Leal } \\
\text { Almeida. }\end{array}$ & & $\begin{array}{l}\text { causadas pelo } \\
\text { câncer infantil no } \\
\text { cotidiano de } \\
\text { familiares de } \\
\text { crianças } \\
\text { neoplasicamente } \\
\text { enfermas. }\end{array}$ & $\begin{array}{l}\text { acompanhando a } \\
\text { criança em } \\
\text { tratamento. }\end{array}$ & & $\begin{array}{l}\text { qualitativa e } \\
\text { enfoque } \\
\text { exploratório- } \\
\text { descritivo }\end{array}$ \\
\hline 7 & $\begin{array}{l}\text { Daniela } \\
\text { Doulavince } \\
\text { Amador; } \\
\text { Isabelle } \\
\text { Pimentel } \\
\text { Gomes; } \\
\text { Altamira } \\
\text { Pereira da } \\
\text { Silva } \\
\text { Reichert; } \\
\text { Neusa Collet. }\end{array}$ & 2013 & $\begin{array}{l}\text { Identificar as } \\
\text { repercussões do } \\
\text { câncer infantil } \\
\text { para o cuidador } \\
\text { familiar }\end{array}$ & & & $\begin{array}{l}\text { Revisão } \\
\text { integrativa da } \\
\text { literatura }\end{array}$ \\
\hline 8 & $\begin{array}{l}\text { Maria da } \\
\text { Graça Corso } \\
\text { da Motta; } \\
\text { Grassele } \\
\text { Denardini } \\
\text { Facin } \\
\text { Diefenbach }\end{array}$ & 2013 & $\begin{array}{l}\text { Identificar } \\
\text { aspectos que } \\
\text { demonstrem as } \\
\text { dimensões da } \\
\text { vulnerabilidade no } \\
\text { universo familiar } \\
\text { na ótica da família } \\
\text { de crianças com } \\
\text { dor oncológica em } \\
\text { ambiente } \\
\text { hospitalar. }\end{array}$ & $\begin{array}{l}9 \text { famílias de } \\
\text { crianças com dor } \\
\text { oncológica na } \\
\text { Unidade de } \\
\text { Hematologia e } \\
\text { Oncologia } \\
\text { Pediátrica de um } \\
\text { hospital de grande } \\
\text { porte de Porto } \\
\text { Alegre-RS }\end{array}$ & $\begin{array}{l}\text { Rio Grande } \\
\text { do Sul }\end{array}$ & $\begin{array}{l}\text { Pesquisa do tipo } \\
\text { descritivo- } \\
\text { exploratório } \\
\text { de abordagem } \\
\text { qualitativa, }\end{array}$ \\
\hline 9 & $\begin{array}{l}\text { Thatianne } \\
\text { Almico; } \\
\text { André Faro }\end{array}$ & 2014 & $\begin{array}{l}\text { Caracterizar o } \\
\text { processo de } \\
\text { enfrentamento da } \\
\text { quimioterapia por } \\
\text { cuidadores de } \\
\text { crianças. }\end{array}$ & $\begin{array}{l}11 \text { cuidadores de } \\
\text { crianças em } \\
\text { tratamento } \\
\text { quimioterápico } \\
\text { atendidos em } \\
\text { Casas de Apoio a } \\
\text { crianças com } \\
\text { câncer na cidade } \\
\text { de Aracaju - SE. }\end{array}$ & Sergipe & $\begin{array}{l}\text { Pesquisa } \\
\text { qualitativa, com } \\
\text { análise de } \\
\text { conteúdo } \\
\text { realizada pelo } \\
\text { programa } \\
\text { IRAMUTEQ. }\end{array}$ \\
\hline 10 & $\begin{array}{l}\text { Samkya F. de } \\
\text { O. Andrade; } \\
\text { Railda F. } \\
\text { Alves; } \\
\text { Myriam de O. } \\
\text { Melo; } \\
\text { Maria J. } \\
\text { Rodrigues. }\end{array}$ & 2014 & $\begin{array}{l}\text { Verificar a relação } \\
\text { entre a qualidade } \\
\text { de vida e a } \\
\text { sobrecarga em } \\
\text { cuidadores de } \\
\text { crianças } \\
\text { portadoras de } \\
\text { neoplasia e } \\
\text { assistidas em uma } \\
\text { casa de apoio. } \\
\end{array}$ & $\begin{array}{l}23 \text { cuidadores de } \\
\text { pacientes em } \\
\text { tratamento } \\
\text { quimioterápico ou } \\
\text { radioterápico } \\
\text { acompanhados } \\
\text { pela Casa de Apoio } \\
\text { à Criança com } \\
\text { Câncer em } \\
\text { Campina Grande. } \\
\end{array}$ & Paraíba & $\begin{array}{l}\text { A abordagem do } \\
\text { estudo foi } \\
\text { transversal e } \\
\text { descritiva }\end{array}$ \\
\hline 11 & $\begin{array}{l}\text { Dailon de } \\
\text { Araújo Alves; } \\
\text { Luanna } \\
\text { Gomes da } \\
\text { Silva; } \\
\text { Gyllyandeson }\end{array}$ & 2016 & $\begin{array}{l}\text { Investigar o papel } \\
\text { da religiosidade e } \\
\text { da espiritualidade } \\
\text { como mecanismo } \\
\text { de enfrentamento } \\
\text { utilizado pelos }\end{array}$ & $\begin{array}{l}10 \text { cuidadores } \\
\text { familiares de } \\
\text { crianças } \\
\text { diagnosticadas } \\
\text { com câncer que } \\
\text { estivessem em }\end{array}$ & Ceará & $\begin{array}{l}\text { A pesquisa } \\
\text { desenvolvida } \\
\text { apresentou um } \\
\text { cunho descritivo e } \\
\text { exploratório, com } \\
\text { a utilização de }\end{array}$ \\
\hline
\end{tabular}




\begin{tabular}{|c|c|c|c|c|c|c|}
\hline & $\begin{array}{l}\text { de Araújo } \\
\text { Delmondes; } \\
\text { Izabel Cristina } \\
\text { Santiago } \\
\text { Lemos; Marta } \\
\text { Regina } \\
\text { Kerntopf; } \\
\text { Grayce } \\
\text { Alencar } \\
\text { Albuqerque. }\end{array}$ & & $\begin{array}{l}\text { cuidadores } \\
\text { familiares diante } \\
\text { do câncer infantil. }\end{array}$ & $\begin{array}{l}\text { tratamento } \\
\text { quimioterápico ou } \\
\text { radioterápico no } \\
\text { Instituto de Apoio } \\
\text { à Criança com } \\
\text { Câncer em } \\
\text { Barbalha - CE. }\end{array}$ & & $\begin{array}{l}\text { abordagem } \\
\text { qualitativa. }\end{array}$ \\
\hline 12 & $\begin{array}{l}\text { Amanda } \\
\text { Aparecida } \\
\text { Borges; } \\
\text { Regina } \\
\text { Aparecida } \\
\text { Garcia de } \\
\text { Lima; } \\
\text { Giselle Dupas. }\end{array}$ & 2016 & $\begin{array}{l}\text { Compreender a } \\
\text { experiência da } \\
\text { família ao } \\
\text { estabelecer a } \\
\text { comunicação com } \\
\text { a criança em } \\
\text { relação ao seu } \\
\text { câncer. }\end{array}$ & $\begin{array}{l}7 \text { famílias de } \\
\text { crianças com } \\
\text { câncer que } \\
\text { realizavam } \\
\text { tratamento em uma } \\
\text { Instituição de } \\
\text { Saúde Oncológica } \\
\text { em Minas Gerais. }\end{array}$ & $\begin{array}{l}\text { Minas } \\
\text { Gerais }\end{array}$ & $\begin{array}{l}\text { Estudo de } \\
\text { abordagem } \\
\text { qualitativa }\end{array}$ \\
\hline 13 & $\begin{array}{l}\text { Natalia } \\
\text { Schopf } \\
\text { Frizzo; } \\
\text { Alberto } \\
\text { Manuel } \\
\text { Quintana; } \\
\text { Adelise } \\
\text { Salvagni; } \\
\text { Ângela } \\
\text { Barbieri; } \\
\text { Lenir Gebert. }\end{array}$ & 2015 & $\begin{array}{l}\text { Compreender as } \\
\text { significações } \\
\text { atribuídas pelos } \\
\text { pais acerca do } \\
\text { diagnóstico de } \\
\text { câncer de seus } \\
\text { filhos. }\end{array}$ & $\begin{array}{l}7 \text { pais de crianças } \\
\text { acometidas por } \\
\text { câncer que } \\
\text { estavam em } \\
\text { tratamento em um } \\
\text { hospital público do } \\
\text { Rio Grande do Sul. }\end{array}$ & $\begin{array}{l}\text { Rio Grande } \\
\text { do Sul }\end{array}$ & $\begin{array}{l}\text { Estudo descritivo, } \\
\text { exploratório de } \\
\text { abordagem } \\
\text { qualitativa }\end{array}$ \\
\hline 14 & $\begin{array}{l}\text { Daniela } \\
\text { Fernanda dos } \\
\text { Santos Alves; } \\
\text { Edinêis de } \\
\text { Brito } \\
\text { Guirardello; } \\
\text { Andréa } \\
\text { Yamaguchi } \\
\text { Kurashima. }\end{array}$ & 2013 & $\begin{array}{l}\text { Avaliar o nível de } \\
\text { estresse dos pais } \\
\text { de crianças com } \\
\text { câncer e } \\
\text { identificar } \\
\text { correlações entre } \\
\text { os dados } \\
\text { sociodemográficos } \\
\text { os níveis de } \\
\text { ansiedade. }\end{array}$ & $\begin{array}{l}101 \text { pais ou } \\
\text { responsáveis ou } \\
\text { acompanhantes } \\
\text { com a guarda da } \\
\text { crianças com } \\
\text { câncer que } \\
\text { realizassem } \\
\text { acompanhamento } \\
\text { no ambulatório de } \\
\text { pediatria do } \\
\text { Hospital do Câncer } \\
\text { de São Paulo. }\end{array}$ & $\begin{array}{l}\text { Campinas - } \\
\text { SP. }\end{array}$ & $\begin{array}{l}\text { Estudo descritivo, } \\
\text { transversal, }\end{array}$ \\
\hline 15 & $\begin{array}{l}\text { Kássia Karina } \\
\text { Amorim } \\
\text { Gomes }\end{array}$ & 2015 & $\begin{array}{l}\text { Compreender em } \\
\text { uma perspectiva } \\
\text { fenomenológica } \\
\text { como crianças } \\
\text { com câncer } \\
\text { vivenciam a } \\
\text { doença. }\end{array}$ & $\begin{array}{l}10 \text { crianças de } 7 \text { a } \\
12 \text { anos } \\
\text { acompanhadas } \\
\text { pelo Grupo de } \\
\text { Apoio à Criança } \\
\text { com Câncer } \\
\text { (GACC) em } \\
\text { Manaus. }\end{array}$ & Manaus & $\begin{array}{l}\text { Pesquisa de } \\
\text { natureza } \\
\text { qualitativa e foi } \\
\text { desenvolvida de } \\
\text { acordo com } \\
\text { os preceitos do } \\
\text { método } \\
\text { fenomenológico. }\end{array}$ \\
\hline 16 & $\begin{array}{l}\text { Guilherme } \\
\text { Costa Lopes }\end{array}$ & 2016 & $\begin{array}{l}\text { Identificar o risco } \\
\text { psicossocial das } \\
\text { crianças e seus } \\
\text { cuidadores; } \\
\text { identificar os } \\
\text { comportamentos, } \\
\text { compreensão da } \\
\text { doença, }\end{array}$ & $\begin{array}{l}15 \text { crianças e seus } \\
\text { cuidadores que } \\
\text { realizavam } \\
\text { quimioterapia ou } \\
\text { tivessem realizado } \\
\text { há no máximo } 5 \\
\text { meses por via } \\
\text { venosa ou que }\end{array}$ & São Paulo & $\begin{array}{l}\text { Estudo } \\
\text { transversal, de } \\
\text { delineamento } \\
\text { quali-quantitativo }\end{array}$ \\
\hline
\end{tabular}




\begin{tabular}{|c|c|c|c|c|c|c|}
\hline & & & $\begin{array}{l}\text { tratamento, } \\
\text { prevenção e da } \\
\text { quimioterapia em } \\
\text { crianças com } \\
\text { câncer na faixa } \\
\text { etária de } 6 \text { a } 12 \\
\text { anos }\end{array}$ & $\begin{array}{l}\text { estivesse } \\
\text { realizando } \\
\text { consultas } \\
\text { periódicas em dois } \\
\text { centros de } \\
\text { referencia em } \\
\text { tratamento } \\
\text { quimioterápico de } \\
\text { câncer pediátrico } \\
\text { do centro-oeste } \\
\text { paulista, em } \\
\text { Botucatu-SP. }\end{array}$ & & \\
\hline 17 & $\begin{array}{l}\text { Márcia } \\
\text { Shirley de } \\
\text { Meneses }\end{array}$ & \begin{tabular}{|l|}
2016 \\
\end{tabular} & $\begin{array}{l}\text { Compreender o } \\
\text { itinerário } \\
\text { terapêutico de } \\
\text { crianças com } \\
\text { câncer e suas } \\
\text { famílias em busca } \\
\text { de tratamento no } \\
\text { sistema de saúde } \\
\text { do Ceará. }\end{array}$ & $\begin{array}{l}10 \text { mães de } \\
\text { crianças com } \\
\text { diagnostico de } \\
\text { câncer que fazem } \\
\text { tratamento no } \\
\text { Centro Pediátrico } \\
\text { do Câncer, do } \\
\text { Hospital Infantil } \\
\text { Albert Sabin - CE. }\end{array}$ & Ceará & $\begin{array}{l}\text { Pesquisa } \\
\text { qualitativa, } \\
\text { descritiva }\end{array}$ \\
\hline 18 & $\begin{array}{l}\text { Ana Paula } \\
\text { Kelly de } \\
\text { Almeida } \\
\text { Tomaz }\end{array}$ & \begin{tabular}{|l|l|}
2014 \\
\end{tabular} & $\begin{array}{l}\text { Conhecer o perfil } \\
\text { de acompanhantes } \\
\text { de crianças em } \\
\text { tratamento } \\
\text { oncológico } \\
\text { internadas e } \\
\text { discutir suas } \\
\text { necessidades de } \\
\text { saúde como } \\
\text { subsídio para } \\
\text { atuação de } \\
\text { enfermagem. }\end{array}$ & $\begin{array}{l}17 \text { acompanhantes } \\
\text { de crianças em } \\
\text { tratamento } \\
\text { oncológico } \\
\text { internadas em uma } \\
\text { enfermaria } \\
\text { oncológica de um } \\
\text { Hospital Público } \\
\text { do Rio de Janeiro. }\end{array}$ & $\begin{array}{l}\text { Rio de } \\
\text { Janeiro }\end{array}$ & $\begin{array}{l}\text { Pesquisa } \\
\text { descritiva com } \\
\text { abordagem } \\
\text { qualitativa }\end{array}$ \\
\hline 19 & $\begin{array}{l}\text { Maria } \\
\text { Fernanda } \\
\text { Vasques } \\
\text { Esteves }\end{array}$ & 2015 & $\begin{array}{l}\text { Analisar os } \\
\text { sentidos das } \\
\text { experiências de } \\
\text { um grupo de mães } \\
\text { de crianças e } \\
\text { adolescentes com } \\
\text { câncer com a } \\
\text { terapia } \\
\text { complementar. }\end{array}$ & $\begin{array}{l}15 \text { mães de } \\
\text { crianças e } \\
\text { adolescentes com } \\
\text { cancer em } \\
\text { acompanhamento } \\
\text { terapêutico em } \\
\text { serviço de saúde } \\
\text { localizado no } \\
\text { interior do estado } \\
\text { de São Paulo. }\end{array}$ & São Paulo & $\begin{array}{l}\text { Estudo de } \\
\text { abordagem } \\
\text { qualitativa. }\end{array}$ \\
\hline 20 & $\begin{array}{l}\text { Patrícia } \\
\text { Luciana } \\
\text { Moreira Dias }\end{array}$ & 2014 & $\begin{array}{l}\text { Identificar os } \\
\text { elementos do } \\
\text { processo da } \\
\text { parentalidade na } \\
\text { sobrevivência do } \\
\text { câncer infanto- } \\
\text { juvenil e } \\
\text { apresentar um } \\
\text { modelo teórico } \\
\text { deste processo que } \\
\text { represente a } \\
\text { integração desses } \\
\text { elementos. }\end{array}$ & $\begin{array}{l}9 \text { casais, pais e } \\
\text { mães de crianças e } \\
\text { adolescentes que } \\
\text { sobreviveram ao } \\
\text { câncer infanto- } \\
\text { juvenil que eram } \\
\text { atendidas em uma } \\
\text { entidade } \\
\text { filantrópica do } \\
\text { interior de SP. }\end{array}$ & $\begin{array}{l}\text { Interior do } \\
\text { Estado de } \\
\text { São Paulo }\end{array}$ & $\begin{array}{l}\text { Estudo } \\
\text { qualitativo. }\end{array}$ \\
\hline 21 & $\begin{array}{l}\text { Marina } \\
\text { Noronha }\end{array}$ & 2013 & $\begin{array}{l}\text { Compreender as } \\
\text { vivências de }\end{array}$ & $\begin{array}{l}\text { Crianças com } \\
\text { idade entre } 5 \text { e } 12\end{array}$ & São Paulo & Estudo qualitativo \\
\hline
\end{tabular}




\begin{tabular}{|c|c|c|c|c|c|c|}
\hline & $\begin{array}{l}\text { Ferraz de } \\
\text { Arruda. }\end{array}$ & & $\begin{array}{l}\text { crianças e de seus } \\
\text { cuidadores- } \\
\text { familiares diante } \\
\text { do tratamento da } \\
\text { recidiva. }\end{array}$ & $\begin{array}{l}\text { anos com recidiva } \\
\text { do câncer e seus } \\
\text { cuidadores } \\
\text { principais que } \\
\text { eram atendidas em } \\
\text { centro de } \\
\text { investigação } \\
\text { hematológica de } \\
\text { Campinas - SP. }\end{array}$ & & \\
\hline 22 & \begin{tabular}{|l|} 
Eliane dos \\
Santos \\
Bomfim.
\end{tabular} & 2016 & $\begin{array}{l}\text { Apreender as } \\
\text { representações } \\
\text { sociais de mães } \\
\text { sobre o cuidado de } \\
\text { crianças com } \\
\text { câncer e conhecer } \\
\text { as vivências } \\
\text { relacionadas ao } \\
\text { cuidado que essas } \\
\text { mães dedicam aos } \\
\text { seus filhos. } \\
\end{array}$ & $\begin{array}{l}19 \text { mães de } \\
\text { crianças com } \\
\text { cancer que faziam } \\
\text { parte do Grupo de } \\
\text { Apoio a Crianças } \\
\text { com Câncer } \\
\text { (GACC Sul-BA). }\end{array}$ & Bahia & $\begin{array}{l}\text { Pesquisa } \\
\text { qualitativa }\end{array}$ \\
\hline 23 & $\begin{array}{l}\text { Thais Helena } \\
\text { Castelo } \\
\text { Branco Leite }\end{array}$ & 2013 & $\begin{array}{l}\text { Compreender a } \\
\text { representação dos } \\
\text { irmãos de crianças } \\
\text { com câncer sobre } \\
\text { o câncer infanto- } \\
\text { juvenil, como este } \\
\text { impacta sua vida e } \\
\text { a dinâmica } \\
\text { familiar. }\end{array}$ & $\begin{array}{l}10 \text { irmãos de } \\
\text { crianças e } \\
\text { adolescentes com } \\
\text { câncer e } 8 \text { mães } \\
\text { que realizavam } \\
\text { acompanhamento } \\
\text { na } \\
\text { oncohematologia } \\
\text { do Hospital } \\
\text { Universitário } \\
\text { Oswaldo Cruz. }\end{array}$ & $\begin{array}{l}\text { Recife, } \\
\text { Pernambuco }\end{array}$ & $\begin{array}{l}\text { Estudo } \\
\text { exploratório } \\
\text { descritivo, de } \\
\text { cunho qualitativo. }\end{array}$ \\
\hline 24 & $\begin{array}{l}\text { Kátia Renata } \\
\text { Antunes } \\
\text { Kochla }\end{array}$ & 2014 & $\begin{array}{l}\text { Compreender a } \\
\text { trajetória de } \\
\text { resiliência e o } \\
\text { encontro de } \\
\text { sentido das mães } \\
\text { que vivenciaram o } \\
\text { adoecimento do } \\
\text { filho com câncer. }\end{array}$ & $\begin{array}{l}10 \text { mães que } \\
\text { vivenciaram o } \\
\text { adoecimento do } \\
\text { filho com câncer e } \\
\text { estavam na fase de } \\
\text { acompanhamento } \\
\text { no ambulatório de } \\
\text { hemato-oncologia } \\
\text { pediátrica no } \\
\text { Paraná-RS. }\end{array}$ & $\begin{array}{l}\text { Rio Grande } \\
\text { do Sul }\end{array}$ & $\begin{array}{l}\text { Pesquisa } \\
\text { fenomenológica. }\end{array}$ \\
\hline 25 & $\begin{array}{l}\text { Malueska } \\
\text { Luacche } \\
\text { Xavier Ferreira } \\
\text { de Sousa }\end{array}$ & 2013 & $\begin{array}{l}\text { Compreender os } \\
\text { significados de } \\
\text { experienciar o } \\
\text { câncer infantil sob } \\
\text { a ótica da criança. }\end{array}$ & $\begin{array}{l}8 \text { crianças com } \\
\text { cancer na faixa } \\
\text { etária de escolar, } \\
\text { que recebem apoio } \\
\text { da instituição Casa } \\
\text { da Criança na PB. }\end{array}$ & Paraíba & $\begin{array}{l}\text { Estudo de } \\
\text { abordagem } \\
\text { qualitativa. }\end{array}$ \\
\hline
\end{tabular}

As famílias passam por diversas mudanças e reorganização diante da necessidade de cuidar do filho com câncer, condição esta que repercute em mudanças estruturais, repercussões psicossociais, mudanças nos padrões de comunicação e relacionamentos na família, a relação entre a equipe de saúde e a família, processo que se inicia desde a percepção de alterações no estado geral de saúde, busca pelo diagnóstico da criança e se 
perpetua ao longo de toda a trajetória de vida da criança e da família (SANCHES, NASCIMENTO, LIMA, 2013; ANDRADE et al. 2014; ESTEVES, 2015; DIAS, 2014), com implicações específicas para o cuidado de enfermagem.

A seguir será apresentada a síntese das quatro categorias temáticas intituladas: mudanças estruturais, repercussões psicossociais, repercussões nos padrões de comunicação e relacionamento familiar e a relação entre equipe de saúde e família.

\subsection{Mudanças Estruturais}

A maioria das famílias dos estudos selecionados era composta por mãe, pai e filhos, com baixa escolaridade, baixa renda, a maioria das cuidadoras eram mulheres com média de 30 a 40 anos e desempregadas (MENESES, 2016; TOMAZ, 2014; ESTEVES, 2015).

As relações de gênero e alterações de papeis demonstraram-se presentes no contexto, visto que a maioria das mães abdicou do emprego, outras reduziram as horas de trabalho para acompanhar o tratamento da criança nos centros especializados em oncologia que geralmente eram em local distante de sua residência, enquanto o pai continuava como provedor do lar e ficava com os demais filhos do casal e família (ALVES, GUIRARDELLO, KURASHIMA, 2013; LOPES, 2016; MENESES, 2016; TOMAZ, 2014; ESTEVES, 2015; BOMFIM, 2016; LEITE, 2013).

A família passa por dificuldades e ajustamentos, mudança nos papeis, mudança de lar, dificuldade financeira, pelo fato de que geralmente a mãe abdica do emprego e se dedica ao cuidado exclusivo do filho e acaba tendo que se mudar para perto do centro de oncologia pediátrica deixando os demais membros da família ou gasto excessivo com transporte e materiais para cuidados da criança seja no ambiente hospitalar ou em casa (AMADOR et al., 2013; .ALMICO, FARO, 2014; ANDRADE et al., 2014).

As famílias nas quais a criança é acompanhada em domicílio além de cuidar das necessidades do filho com câncer também cuidam das atividades domésticas e dos demais membros familiares (ANDRADADE et al., 2014).

As famílias passaram por diversas modificações, situações estressoras, incertezas e sofrimento diante do diagnóstico de câncer do filho, inicialmente quando a família observa os sintomas da criança como a inapetência, não querer brincar, cansaço inicia uma busca pelo diagnóstico da criança, que forma um itinerário terapêutico demarcado por demora, diversos hospitais, diagnósticos imprecisos e gasto financeiro (SANCHES; NASCIMENTO; LIMA, 2013). 
A busca pela descoberta das alterações na criança leva a família a procurar diversos médicos e clínicas, que pela inespecificidade dos sintomas não obtém diagnóstico preciso, e diante de tal imprecisão e incerteza a família se sente insegura e receosa por não conseguirem descobrir o que o filho apresenta, até encontrarem um especialista, oncologista que dá a criança e família o diagnóstico de câncer infantil (BORGES, LIMA, DUPAS, 2016; FRIZZO et al., 2015).

Após a confirmação do diagnóstico são ocasionadas diversas mudanças na rotina da família que trazem consequentemente problemas financeiros, emocionais e psicossociais, além da ansiedade e depressão conflitos conjugais, dificuldade de relacionamento com os outros filhos que ficam com outros membros familiares, afastamento social, mudança de planos de vida, todos os planos são abandonados e deixados para um futuro incerto, de quando o filho se recuperar (SANCHES, NASCIMENTO, LIMA, 2013; AMADOR et al., 2013; MOTTA, DIEFENNACH, 2013; ALMICO, FARO, 2014).

A família torna o filho doente o centro do cuidado e atenção abdicando de todas as atividades diárias e de vida em prol do filho, tais modificações familiares provocam sobrecarga, desgaste e sofrimento na família (SANCHES, NASCIMENTO, LIMA, 2013; AMADOR et al., 2013; MOTTA, DIEFENBACH, 2013; ALMICO, FARO, 2014).

O sofrimento das famílias de crianças com câncer é atenuado quando elas encontram sistemas de apoio. Os sistemas de apoio vêm de fontes diversas, como de famílias de outras crianças que estão passando pela mesma situação, de familiares ou amigos que se sintam comovidos e auxiliem a família no processo de ajustamento e adaptação seja financeiramente ou ajudando no cuidado com os demais membros da família, da equipe de saúde que auxilia a família e/ou realiza os cuidados com a criança e também se mantém em vigilância assim como a família, e da religiosidade que faz com que a família mantenha a esperança e acredite na cura (SANCHES, NASCIMENTO, LIMA, 2013; AMADOR et al., 2013; ALMICO, FARO, 2014).

As famílias de crianças com câncer vivenciam mudanças financeiras, emocionais e psicossociais que influenciam a dinâmica familiar, mas que também permitem o desenvolvimento de estratégias positivas de enfrentamento (BERNARDES, PEGORARO, 2015; ALVES et al., 2016; BORGES, LIMA, DUPAS, 2016; ESTEVES, 2015).

A religiosidade é uma das principais formas de enfrentamento manejada pelas famílias de crianças com câncer, a fé e o amor pelo filho faz com que as famílias mantenham-se esperançosas e acreditem na cura da doença e transmitem tais sentimentos e sentidos para a 
criança, que se espelha na família e também utiliza a esperança para enfrentamento das situações estressoras como os procedimentos, mal estar e preconceitos que também levam sofrimento a criança (SANCHES, NASCIMENTO, LIMA, 2013; ALMICO, FARO, 2014; ALVES et al., 2016).

\subsection{Repercussões Psicossociais}

O diagnóstico do câncer infantil também é um momento permeado de sentimentos negativos, sentimentos de ansiedade, incerteza, desespero e medo, medo do que a doença representa segundo a simbologia e estigmas aprendidos socialmente pela família, medo da perda do filho, medo da perda dos sonhos e do que a família era para o que se tornará (BORGES, LIMA, DUPAS, 2016; FRIZZO et al., 2015; KOCHLA, 2014).

A partir do diagnóstico a família busca compreender o que aconteceu e retoma atitudes individuais e em família. Nesse sentido as famílias desenvolvem intenso sentimento de culpa, de impotência por não ter conseguido proteger o filho, pensando que ele teve a doença por falta de cuidados, de presença efetiva de seus membros e até mesmo como um castigo divino, o que intensifica o sofrimento familiar (BOMFIM, 2016).

Os sentimentos de ansiedade, incerteza, depressão, sentimento de querer desistir da vida e medo são presentes nas famílias das crianças com câncer desde o diagnóstico até mesmo após o tratamento devido à chance de recidiva (AMADOR et al., 2013; MOTTA, DIEFENBACH, 2013; ALMICO, FARO, 2014; ALVES, GUIRARDELLO,KURASHIMA, 2013). Os sentimentos negativos são intensificados quando a criança apresenta sinais de piora ou em decorrência dos efeitos colaterais da quimioterapia e radioterapia, como a queda de cabelo, emagrecimento (KOCHLA, 2014).

No momento de piora da criança a família tende a desenvolver mais cuidados com a criança, com a alimentação, com o convívio social, inclusive afastando pessoas pelo medo de infecções e outras intercorrências que possam ocorrer. A criança e família percebem o afastamento social mesmo de amigos que antes eram próximos e o estigma que a doença traz quando ao sair com o filho para fora do ambiente hospitalar com chapéus, bonés e máscaras sofrem olhares e preconceito (ANDRADE et al., 2014; DIAS, 2014; BOMFIM, 2016).

A família vê o cuidado do filho como seu dever, não como obrigação e apesar do sentimento de sobrecarga, mantém-se dedicada ao cuidado do filho, sem querer passar essa tarefa para outras pessoas do seu sistema de apoio, mesmo que sejam familiares próximos (AMADOR et al., 2013; SANCHES, NASCIMENTO, LIMA, 2013). 
A criança percebe o adoecimento com os primeiros sintomas, principalmente quando se sente cansada e não sente vontade de brincar, ou mesmo pela necessidade de hospitalização. As crianças experienciam sentimentos negativos com a doença e tratamento se sentem tristes pela necessidade de afastamento de casa, da família, das atividades escolares, colegas, para realização do tratamento, percebem também as modificações familiares, referem os procedimentos como dolorosos, não gostam da alimentação hospitalar, além das mudanças na sua autoimagem decorrente da quimioterapia, o que gera muito sofrimento para a criança (SIQUEIRA et al., 2015; GOMES, 2015; ESTEVES, 2015; SOUSA, 2013).

As crianças apresentam distintos comportamentos, desde comportamentos de rebeldia, como se fechar em seu mundo e se isolar. A criança aprende com a doença que está no mundo para o que vier o que pode causar sensação de desamparo (SIQUEIRA et al., 2015; GOMES, 2015; SOUSA, 2013).

As crianças ao se depararem com a morte de outras crianças veem a morte como possibilidade, entretanto, a influência familiar tem a capacidade de levar esperança a elas, fazendo com que vejam a hospitalização e os procedimentos como forma de obter a cura e então se submetem a eles (SIQUEIRA et al., 2015; GOMES, 2015; ESTEVES, 2015; SOUSA, 2013).

As crianças manejam assim como a família formas de enfrentamento como a fé que os fazem pensar no futuro mesmo que após a cura, acreditar nos procedimentos e realizar ações de fuga como ouvir música, assistir TV ou até mesmo fantasiar (LOPES, 2016).

Os irmãos saudáveis de crianças com câncer compreendem a doença e sua gravidade, sentem-se preocupados e adotam medidas de cuidado com o irmão. Apesar de tal entendimento o irmão saudável pode ter comportamentos negativos como isolamento, depressão, por ser uma criança que também está em desenvolvimento e que também necessita de atenção e cuidados, e nesse momento fica afastado ou com demais parentes para que o foco da família seja o irmão doente. Dessa forma a própria relação de irmãos pode ser abalada devido ao afastamento, mas mesmo assim o irmão saudável entende pela conjuntura familiar que este é o momento de cuidar do irmão doente, então participa dos cuidados e auxilia a família (BERNARDES, PEGORARO, 2015; LEITE, 2013).

O irmão saudável ao cuidar do irmão com câncer desenvolve também aspectos positivos como a responsabilidade e amadurecimento, valorizando mais aspectos cotidianos e atividades em família (BERNARDES, PERGORARO, 2015; LEITE, 2013). 
Apesar dos pontos negativos, alguns pontos positivos são vistos na família que enfrenta o câncer infantil, como por exemplo, as mães que não eram as principais responsáveis pelo cuidado do filho antes do adoecimento da criança, passam a acreditar e desenvolver ações de responsabilidade e cuidado com a criança, e desenvolvimento de melhor vínculo com o filho, assumindo de fato o seu papel de mãe. As famílias também descobrem a união, o companheirismo, criam vínculos com outras pessoas de ciclos sociais que não tinham antes do adoecimento da criança, fortalecem vínculos já existentes e encontram na fé força para enfrentar demais situações que surgirem (MEDEIROS et al., 2014).

A recidiva do câncer da criança traz novamente todos os sentimentos negativos que a família passou na primeira vez, mais os sentimentos de fracasso, impotência e luto antecipado, trocando a superproteção pela vivência do agora, deixando de pensar em planos futuros, mas ainda assim manejam a religiosidade, a crença e a fé para lidar com a situação (ESTEVES, 2015; DIAS, 2014; ARRUDA, 2013).

\subsection{Mudanças nos Padrões de Comunicação e Relacionamento Familiar}

O adoecimento da criança traz modificações importantes nos padrões de comunicação e na estrutura familiar. Alguns familiares optam por não falar abertamente com a criança sobre a doença, enquanto outras falam, mas as famílias sempre mantem o diálogo demonstrando a importância da criança aceitar os procedimentos relacionando-o com a cura. As crianças com as quais a família fala sobre sua condição possuem mais informações e melhor enfrentamento em gerir as situações estressoras inerentes ao tratamento (BORGES, LIMA, DUPAS; LOPES, 2016).

Nos casos de recidiva a comunicação da família com a criança também se modifica de forma que muitas famílias não falam abertamente com a criança sobre o retorno da doença, falam pouco e dão somente as informações essenciais na tentativa de protege-la o máximo possível (ARRUDA; 2013).

A recidiva também é um momento em que há alteração importante da comunicação entre a família e a criança. A família evita falar abertamente que a doença retornou, a família tenta proteger a criança dando somente as informações que considera de extrema importância. (ARRUDA-COLLI, SANTOS; 2013).

As modificações na rede social familiar (relações de trabalho, limitações das atividades de lazer entre outras da vida diária e constante necessidade de contato com os serviços de saúde para cuidar da criança com câncer) têm repercussões nos relacionamentos 
internos da família, especialmente na relação conjugal, entre pais e filhos e entre irmãos. (AMADOR et al., 2013; ALMICO, FARO, 2014; ANDRADADE et al., 2014). Cria-se um subsistema mãe-filho com câncer, caracterizado por maior proximidade, preocupação e direcionamento de cuidado e maior aproximação da avó que auxilie nos cuidados com a criança.

As famílias modificam seus relacionamentos interpessoais ao passo que com o adoecimento da criança perdem o convívio social que mantinha anteriormente com amigos e familiares. As famílias tendem a se isolar diante da nova realidade e seu meio social se torna o ambiente hospitalar, desenvolvendo maior vínculo com avós, irmãos, pessoas que compreendam sua situação, familiares de outras crianças com câncer que fazem tratamento no mesmo local que seu filho, igreja e profissionais (SANCHES, NASCIMENTO, LIMA, 2013; AMADOR et al., 2013)

As modificações na estrutura familiar e o enfrentamento de tais situações em decorrência do tratamento da criança também trazem mudanças no relacionamento familiar, como a criação de subsistemas familiares, nos quais normalmente por ficar com a mulher o papel de cuidadora, avó e mãe se unem para cuidar da criança, enquanto os demais membros familiares cuidam do sustento financeiro, do resto da família e se apoiam. Nesse momento podem surgir divergências conjugais, pois é onde a mulher espera receber o apoio do marido e vice-versa (MOTTA, DIEFENBECH, 2013; ANDRADADE et al., 2014).

O relacionamento com o irmão saudável sofre alterações devido ao afastamento do convívio entre irmãos, pela família colocar o irmão doente como foco de cuidado, se esquecendo das necessidades psicossociais e emocionais do irmão saudável (BERNARDES, PEGORARO, 2015; LEITE, 2013).

O adoecimento da criança também proporciona aqueles que não mantinham bom vínculo afetivo com o filho um fortalecimento desse relacionamento diante das necessidades de cuidado contínuo e atento (MEDEIROS et al., 2014).

O enfrentamento da situação também proporciona a família mais união, companheirismo no parceiro para enfrentar essa e outras situações, o que também modifica a visão da família quanto a vida em si, apoio mútuo entre o casal, tomada de decisões sobre a vida familiar conjunta, pensando a melhor organização possível para a família (ANDRADE et al, 2014; DIAS, 2014). 
Apesar do intenso sofrimento vivido os pais acreditam ter passado por um crescimento importante e que após as dificuldades e modificações estão mais pertos de Deus e da própria família (DIAS, 2014).

A recidiva do câncer também traz importantes modificações no relacionamento familiar, principalmente porque é um momento em que a família deixa um pouco de lado a superproteção para viver e aproveitar cada momento com a criança (ARRUDA; 2013).

As famílias de crianças que vivenciaram o câncer infantil e sobreviveram são influenciadas por essa vivência na criação dos filhos, planejam o futuro e querem sempre que o filho seja o melhor que puder fazendo tudo para que o filho dê certo na vida, entretanto tem outro ponto que é o fato de não terem coragem de dizer não a criança que teve experiências dolorosas e desagradáveis na infância (DIAS, 2014).

\subsection{A relação entre a equipe de saúde e a família}

A equipe de saúde desempenha importantes papeis de forma a auxiliar a família no processo de adaptação, como manter boa comunicação com a família e a criança no decorrer do diagnóstico, tratamento e acompanhamento da criança e família mesmo após tratamento, assim como o fornecimento de informações que auxilia a família a compreender melhor a doença, procedimentos, intercorrências, de forma a minimizar o sofrimento familiar, a culpabilização, receios e incertezas, o que permite um melhor enfrentamento e adaptação da experiência familiar, que consequentemente influencia o enfrentamento da criança (BERNARDES, PEGORARO, 2015; ALVES et al., 2016; BORGES, LIMA, DUPAS, 2016; ESTEVES, 2015).

A falta de informação por parte dos profissionais de saúde fazem com que a família se sinta mais insegura e desesperançosa (AMADOR et al., 2013). Os sentimentos negativos de incerteza e insegurança decorrentes da má comunicação entre a família e a equipe de saúde são repassadas para crianças (ALVES et al., 2016).

A linguagem técnica dos profissionais e a forma de abordagem associada a falta de comunicação adequada dificulta o entendimento da família quanto a piora da criança, principalmente em um momento confuso como a notificação da equipe de cuidados paliativos e perda da chance de cura do câncer. A falta de informações leva a família a ficar confusa com o conceito de cuidados paliativos e achar que o ambiente hospitalar seria o melhor local para a criança (SANCHES, NASCIMENTO, LIMA, 2013). 
A orientação adequada da família permite melhor enfrentamento e reorganização familiar, uma vez que a equipe torna-se uma fonte de apoio. Esse apoio também permite a família olhar também para o irmão saudável, é importante a equipe proporcionar ambiente de escuta e de fala para o irmão saudável de forma que a ajuda-lo a lidar com os sentimentos (BERNARDES, PEGORARO, 2015).

$\mathrm{Na}$ recidiva a comunicação da equipe com a família e a criança também sofrem alterações, ao passo que a equipe de saúde tenta manter um diálogo aberto com a criança ao falar da doença e de seu retorno e a família tenta proteger a criança dando apenas as informações que considera essenciais (ARRUDA-COLLI, SANTOS; 2013).

As famílias percebem e reconhecem o apoio da equipe de enfermagem, veem-na como presente nos momentos mais difíceis e habilitados para cuidar da criança com câncer (KOCHLA, 2014) principalmente quando se faz necessária a realização de procedimentos e cuidados que a família não se sente capacitada a prestar devido ao conhecimento técnicocientífico envolvido no processo de cuidar em oncologia pediátrica e confia tal cuidado a equipe de enfermagem ao sentir confiança pelas informações, apoio e afeto recebidos (TOMAZ, 2014).

As informações permitem a família melhor compreensão sobre o câncer do filho e procedimentos decorrente do tratamento e consequentemente melhor enfrentamento do tratamento da criança (AMADOR et al., 2013). Nesse contexto a equipe de saúde se torna um sistema de apoio importante que auxilia a família a manter um enfrentamento mais positivo das dificuldades enfrentadas em toda sua trajetória desde o adoecimento do filho, durante e pós tratamento (KOCHLA; 2014). 


\section{DISCUSSÃO}

As famílias de crianças com doença crônica ou complexa requerem o desenvolvimento de habilidades para obter um enfrentamento positivo quanto à doença da criança e das modificações advindas com ela, visando reorganização e adaptação de modo que ocorra a manutenção da vida familiar. Nesse contexto, elas devem ser capazes de: aceitar a doença da criança, gerenciar a condição, atender as necessidades de desenvolvimento da criança e dos outros membros, lidar com o estresse e as crises, educar os outros familiares e desenvolver sistemas de apoio (DOCHERTY et al., 2014).

A adaptação da família requer o desenvolvimento de habilidades conquistadas a partir do desenvolvimento de estratégias para que consiga lidar com a condição crônica ou complexa na criança, iniciando com a orientação adequada da família, sendo assim a enfermagem pode promover encontro multidisciplinar para orientação de todos os membros da família quanto à condição da criança, restrições, tratamento, procedimentos, possível futuro, avaliando o nível de entendimento e de aceitação das informações pela família em diferentes momentos, repetindo as informações constantemente para que compreendam o que está acontecendo e o que é da condição crônica da criança. (DOCHERTY et al., 2014).

A falta de comunicação adequada das famílias influenciam o desenvolvimento e manutenção de sentimentos negativos, portanto cuidado da criança com doença crônica deve estar pautado em um cuidado voltado para as necessidades da família, sendo um dos papeis da enfermagem propiciar a formação de vínculo com a família, boa comunicação, relacionamento horizontal de forma a compreender os sentimentos e comportamentos da família e estratégias de enfrentamento valorizando-a e incluindo-a no plano assistencial (AZEVEDO et al., 2012).

Na nova condição da criança e da família com a doença crônica as relações de papeis se modificam ficando o pai como provedor do lar, enquanto a mãe se torna a responsável pelos cuidados e acompanhamento da criança com câncer (OLIVEIRA et al., 2015), divisão esta em que as mães acabam deixando o emprego, o lar e os demais membros para acompanhar a criança, causando maior mais sofrimento familiar e maiores dificuldades financeiras (CASTRO, 2010; OLIVEIRA et al., 2015).

A enfermagem deve orientar as famílias de crianças com condição crônica ou complexa sobre as modificações familiares e de papeis que ocorrem devido às necessidades de cuidado constante da criança, sobre a importância da participação de ambos os pais nos cuidados, distribuir as atividades para todos os membros familiares, estabelecer descanso com 
certa periodicidade para os envolvidos nos cuidados, conversar com a família quanto às dificuldades financeiras e os medos que podem permear a família, os cuidados que devem ser realizados com a criança mesmo ela estando em casa, as dificuldades que a família possa passar de forma a minimizar os conflitos e estresses, incluindo a família no plano assistencial e na tomada de decisão quanto aos cuidados desenvolvidos com a criança (DOCHERTY et al., 2014).

A enfermagem deve encorajar práticas de normalização da rotina e da vida familiar por meio de diferentes atividades para que a criança e família mantenham seu desenvolvimento, dentre esses cuidados está ensinar criança e família a lidar com os estigmas da doença, mostrando a criança como utilizar roupas, objetos e perucas que disfarcem as alterações como a queda de cabelo, de forma a reduzir o impacto negativo sobre a autoimagem da criança, e sentimentos negativos na família, realizar encenação de papeis que auxiliem a criança a desenvolver respostas preparatórias quando questionada sobre sua condição, elaborar um plano conjunto com a escola para que as crianças da escola também sejam preparadas e compreendam as modificações no colega, orientar a família a permitir que a criança realize as atividades que conseguir com maior nível de independência possível, estimular a socialização como os passeios e atividades escolares para que a criança mantenha seu desenvolvimento (DOCHERTY et al., 2014).

As famílias de crianças em condição crônica acabam sofrendo um distanciamento dos filhos saudáveis e dos demais membros familiares pela necessidade constante de internações e cuidados demandados pela criança influenciando suas relações. (SILVA et al., 2010)

A enfermagem deve incluir demais membros assim como o irmão nas orientações e cuidados, colocando-o como integrante ativo da família e do plano de cuidados, encorajandoo a conversar com os pais sobre seus sentimentos e também fazer um trabalho com os pais para que eles não fiquem focados apenas no filho com condição crônica, mas se atentem as necessidades do outro filho, que o elogiem, deem recompensas de forma a promover o seu bom desenvolvimento também (DOCHERTY et al., 2014).

A vida da família é extremamente modificada desde o diagnóstico da doença crônica da criança sendo permeada por medo constante, sentimentos de insegurança, estresse, sobrecarga e esgotamento que são sentidos e referidos pelas famílias (SILVA et al., 2010). O medo da perda do filho é constante, ainda mais quando essas mães veem outras crianças morrerem pelo câncer, pela chance de recidiva, além dos sentimentos de angústia, dos 
estigmas da doença e suas representações que desenvolvem ainda mais os sentimentos negativos. (CASTRO, 2010; OLIVEIRA et al., 2015)

O afastamento do lar é um dos fatores contribuintes para que ocorram os conflitos em famílias de crianças com doenças crônicas, principalmente se a relação familiar já era conflituosa antes do surgimento da doença, o que pode levar até a separação do casal (SILVA et al., 2010) porém também há casos em que os casais mantêm bom diálogo e reconhecem o afastamento como necessário para o cuidado da criança com câncer, fortalecendo a união (CASTRO, 2010).

A enfermagem deve orientar as famílias de crianças com condição crônica ou complexa a quanto as possíveis intercorrências e sinais que fogem a condição da criança e a necessidade da família buscar o hospital nos momentos de crise, e também sobre as consequências da hospitalização, como a necessidade de nesses momentos um membro ficar com a criança enquanto o outro fica com o restante da família e que consequentemente quem estiver com os outros membros vai estar menos envolvido nos cuidados diretos, incentivar os pais a discutir seus sentimentos, o impacto da doença na família, mantendo o diálogo entre si e com outros pais que estão passando pela mesma situação de doença crônica complexa na família reduzindo o nível de estresse e conflitos familiares (DOCHERTY et al., 2014).

As famílias de crianças com doenças crônicas utilizam diferentes formas de apoio, como a religião e familiares próximos (NÓBREGA et al.,2010), mas também buscam apoio em pessoas que vivenciam a mesma situação e profissionais de saúde, sendo a religiosidade um dos sistemas mais acessados e de importante valor, uma vez que a necessidade de acreditar em algo maior desenvolve um enfrentamento melhor dos estresses vivenciados pelas famílias, transmitindo segurança e sentimentos positivos que vão além da capacidade dos demais recursos (NÓBREGA et al., 2010). A religião é muito acessada como forma encarar o próprio medo da morte da criança e na mobilização da esperança. (SILVA et al., 2010).

Os avós demonstram ser um importante auxílio e recurso para as famílias de crianças com doenças crônicas, e é o membro de maior confiança da família na ausência dos pais, principalmente se a família tem outros filhos e necessita se afastar do lar e deixá-los com demais familiares (SILVA et al. 2010).

A enfermagem pode promover ou encaminhar a família para grupos com familiares de pais com crianças em condição crônica complexa formando um sistema de apoio emocional e social e aumentar as redes sociais dessas famílias, buscar ajuda financeira disponível pelo 
sistema de saúde junto à assistência social, apoiar a família a mobilizar sua espiritualidade e respeitá-la, demonstrar a família suas potencialidades mantendo-se aberta à comunicação e como um dos sistemas de apoio disponíveis para a família (DOCHERTY et al., 2014).

Apesar do intenso sofrimento as famílias relatam aspectos positivos em decorrência do câncer da criança, como formação de vínculos entre os próprios membros, com outras redes, crescimento e aprendizado com as demandas decorrentes do adoecimento e a adaptação familiar (CASTRO, 2010).

O cuidado de enfermagem deve, portanto estar pautado no cuidado centrado na família que visa o desenvolvimento da criança e da família mesmo em condição crônica complexa, sendo esta uma ferramenta importante que auxilia a compreender melhor as dinâmicas, vivência e enfrentamento familiar (DOCHERTY et al., 2014) para que o cuidado seja planejado e realizado de acordo com as necessidades psicossociais, emocionais e espirituais da criança e família auxiliando o desenvolvimento de ambas e de habilidades para melhor enfrentamento e reorganização familiar que mantenha o funcionamento e a qualidade de vida familiar (AZEVEDO et al., 2012). 


\section{CONSIDERAÇÕES FINAIS}

O estudo permitiu compreender as principais repercussões físicas, psicológica, financeira, sociais e emocionais na vida familiar. As principais repercussões encontradas foram estruturais, psicossociais, nos padrões de comunicação e relacionamento familiar e na relação da família com a equipe de saúde.

As mudanças estruturais como deixar o lar, os demais filhos, o emprego e a vida social, as modificações financeiras acarretam importantes repercussões psicossociais na família que necessita de se reorganizar para lidar com o diagnóstico e tratamento da criança e manter o lar.

O diagnóstico e tratamento da criança geram um estresse intenso na família, permeado por medo da perda do filho, incertezas quanto ao futuro, ansiedade, angústia, principalmente se a família não for orientada de forma adequada.

A família desenvolve importantes mecanismos de enfrentamento da situação, como o desenvolvimento de relações com outras famílias que passam pela mesma situação, fortalecimento de vínculo com familiares e próximos e relacionamento com a equipe de saúde, principalmente com a enfermagem que tem se demonstrando como principal cuidadora presente e importante papel na comunicação e estreitamento de laços entre a família e a equipe de saúde.

O enfermeiro deve promover cuidado centrado na criança e família, permitindo que a família faça parte dos cuidados e processo de tomada de decisão quanto aos cuidados que envolvem seu filho. A enfermagem também deve promover espaço de escuta qualificada, de troca de experiências entre as famílias que estão realizando tratamento, de forma a auxiliar a família no seu desenvolvimento e adaptação a reorganização familiar, respeitando as crenças e reforçando a espiritualidade e fé como forma de enfrentamento positivo do câncer infantil e as modificações familiares.

As limitações do estudo foram o fato dele ser nacional e da pesquisa ter sido realizada nas bases de dados de acesso irrestrito à universidade, sendo importante que demais pesquisas explorem também conteúdos internacionais. Dentre as lacunas encontradas se faz necessária maior investigação da relação e sentimentos do pai em relação as repercussões do câncer infantil que quase não foi encontrado em literatura.

Esse estudo demonstra importante contribuição para a enfermagem, profissão que mantém contato contínuo com a unidade criança-família, pois a compreensão da família como parte integrante e inerente nos cuidados permite um olhar holístico, humanizado e integração 
da família o que auxilia em um melhor enfretamento pela unidade familiar, questão essencial no cuidado à criança com câncer e sua família. 


\section{REFERÊNCIAS}

(1) Instituto Nacional do Câncer (Brasil)/ Ministério da Saúde (Brasil). Incidência do câncer na infância de 0-19 anos: II crianças e adolescentes - Perfil. Disponível em:

<http://www1.inca.gov.br/wcm/incidencia/2017/pdf/faixa-etaria/criancas-adolescentes-0-19anos-perfil.pdf $>$. Acesso em: 15 de maio 2018.

(2) Instituto Nacional do Câncer (Brasil). Ministério da Saúde (Brasil). Mortalidade de crianças com câncer de 0-19 anos: Perfil - Todas as neoplasias. Disponível em: $<$ http://www1.inca.gov.br/wcm/incidencia/2017/pdf/mortalidade-criancas-adolescentesadultos-jovens-0-29-anos.pdf.> Acesso em: 15 de maio de 2018.

(3) Instituto Nacional do Câncer (INCA)/ Ministério da Saúde (Brasil). TUMORES INFANTIS. Disponível em:

<http://www1.inca.gov.br/tumores_infantis/pdf/livro_tumores_infantis_0904.pdf>. (Acesso em: 15 de maio de 2018).

(4) Instituo Nacional do Câncer (Brasil). Tipos de câncer: infantil. Disponível em: <http://www.inca.gov.br/wps/wcm/connect/tiposdecancer/site/home/infantil>. Acesso em: 15 de maio de 2018.

(5) Steliarova-Foucher E, Stilller C, Lacour B, Kaatsch P. Classificação Internacional do Câncer na Infância. John Wile and Sons, Ltd: (INCA); 2009. (Publicação científica; $n^{\circ} 7$ ).

(6) Ballard NR. Estrutura familiar, Função e Processo. In: HANSON, Shirley May Harmon. Enfermagem de Cuidados de Saúde à Família. Segunda edição. Lusociência, 2005. Capítulo 4. p. 85-107.

(7) Barreto SFA. Os impactos do câncer infantil no contexto familiar. Brasília-DF. Artigo [bacharel em saúde coletiva] - Universidade Católica de Brasília; 2014.

(8) Lawrenz P, Peuker ACWB, Castro EK. Percepção da Doença e Indicadores de TEPT em Mães de Sobreviventes de Câncer Infantil. Temas em Psicologia. 2016; 24(2): 427-438.

(9) Dias AL. Convicções de saúde e câncer infantil: um estudo de familiares em casas de apoio. Dissertação [mestrado em Psicologia da Saúde] - Universidade Metodista de São Paulo; 2016.

(10) Marques G. A família da criança com câncer: necessidades sócio-econômicas. Rev Gaúcha Enferm. 2017; 38(4): 1-8. 
(11) Mendes KDS, Silveira RCCP, Galvão CM. Revisão integrativa: método de pesquisa para a incorporação de evidências na saúde e na enfermagem. Texto Contexto Enferm. 2008 outdez; 17(4): 758-64.

(12) Souza MT, Silva MD, Carvalho R. Revisão integrativa: o que é e como fazer. Einstein. 2010; 8 (1): 102-106.

(13) Costa AP. Processo de construção e avaliação de artigos. Rev. Esc. Enferm. USP. 2016; 50 (6): 890-891.

(14) Sanches MVP, Nascimento LC, Lima RAG. Crianças e adolescentes com câncer em cuidados paliativos. Rev Bras Enferm. 2014 jan-fev; 67 (1): 28-35.

(15) Andrade SFO, Alves RF, Melo MO, Rodrigues MJ. Psicol., Ciênc. Prof. 2014; 34 (4): 1014-1031.

(16) Esteves MFV. Os sentidos das experiências de mães de crianças e adolescentes oncológicos com terapia complementar. Ribeirão Preto - SP. Dissertação [mestre em ciências] - Universidade de São Paulo; 2015.

(17) Dias PLM. Alerta e proteção parental na sobrevivência do câncer do filho. São Paulo. Tese [doutorado em ciências] - Universidade de São Paulo; 2014.

(18) Meneses MS. Itinerários terapêuticos de famílias em busca de atendimento para seus filhos com câncer. Ceará. Dissertação [mestrado em saúde coletiva] - Universidade Estadual do Ceará; 2016.

(19) Tomaz APKA. Necessidades de acompanhante mãe de criança internada para tratamento oncológico: subsídios para atuação da enfermagem. Rio de Janeiro. Dissertação [mestrado em enfermagem] - Universidade Federal do Estado do Rio de Janeiro; 2014.

(20) Alves DFS, Guirardello EB, Kurashima AY. Estresse relacionado ao cuidado: o impacto do câncer infantil na vida dos pais. Rev. Latino-Am. Enfermagem jan-fev 2013; 21 (1): 1-7.

(21) Lopes GC. A compreensão da doença, do tratamento quimioterápico e as formas de enfrentamento de crianças com câncer. Botucatu - SP. Dissertação [mestrado em saúde coletiva] - Universidade Estadual Paulista; 2016. 
(22) Bomfim ES. Representações de mães sobre o cuidado de crianças com câncer. Bahia. Dissertação [mestrado em enfermagem e saúde]; 2016.

(23) Leite THCB. Convivendo com o câncer infanto-juvenil: representação do irmão saudável acerca da doença. Recife. Dissertação [mestrado em saúde da criança e do adolescente] Universidade Federal de Pernambuco; 2013.

(24) Amador DD, Gomes IP, Reichert APS, Collet N. Repercussões do câncer infantil para o cuidador familiar: revisão integrativa. Rev Bras Enferm. 2013 mar-abr; 66 (2): 267-270.

(25) Amador DD, Reichert APS, Lima RAG, Collet N. Concepções de cuidado e sentimentos do cuidador de crianças com câncer. Acta Paul Enferm. 2013; 26 (6): 542-546.

(26) Almico T, Faro A. Enfrentamento de cuidadores de crianças com câncer em processo de quimioterapia. Psic., Saúde \& Doenças. 2014 dez.; 15(3): 723-737.

(27) Borges AA, Lima RAG, Dupas G. Segredos e verdades no processo comunicacional da família com a criança com câncer. Esc Anna Nery 2016; 20 (4): 1-8.

(28) Frizzo NS, Quitana AM, Salvagni A, Barbieri A, Gebert L. Significaões dadas pelos progenitores acerca do diagnóstico do câncer dos filhos. Psicol., Ciênc. Prof. 2015; 35 (3): 959-972.

(29) Motta MGC, Diefenbach GDF. Dimensões da vulnerabilidade para as famílias da criança com dor oncológica em ambiente hospitalar. Esc Anna Nery. 2013 jul-set; 17 (3): 482-490.

(30) Alves DA, SILVA LG, Delmondes GA, Lemos ICS, Kerntopf MR, Albuqerque GA. Cuidador de criança com câncer: religiosidade e espiritualidade como mecanismos de enfrentamento. Rev Cuid. 2016; 7 (2): 1318-1324.

(31) Arruda-Colli MNF, Santos MA. Aspectos psicológicos da recidiva em oncologia pediátrica: uma revisão integrativa. Arq. bras. psicol. 2015; 67 (3): 75-93.

(32) Kochla KRA. O encontro do sentido: uma luz para a trajetória resiliente das mães que vivenciaram o câncer. Curitiba-PR. Tese [doutorado em enfermagem] - Universidade Federal do Paraná; 2014. 
(33) Siqueira HBOM, Santos MA, Gomez RRF, Saltareli S, Sousa FAEF. Expressão da dor na criança com câncer: uma compreensão fenomenológica. Estd. psicol. 2015 out-dez; 32 (4): 663-674.

(34) Gomes KKA. E a vida sofre transformações: compreendendo a vivência de crianças com câncer à luz da psicologia fenomenológico-existencial. Manaus. Dissertação [mestrado em psicologia] - Universidade Federal do Amazonas; 2015.

(35) Sousa MLXF. Significados do viver com o câncer para a criança. João Pessoa - PB. Dissertação [ mestrado em enfermagem] - Universidade Federal da Paraíba; 2013.

(36) Bernardes IA, Pegoraro RF. Irmãos saudáveis de criança com câncer: revisão integrativa da literatura. Reps. 2015 out-dez; 16 (14): 98-108.

(37) Medeiros EGMS, Leite RFB, Ramos DKR, Almeida LAL. Repercussões do câncer infantil no cotidiano do familiar cuidador. Rev Rene. 2014 mar-abr; 15 (2): 233-239.

(38) Arruda MNF. A recidiva do câncer pediátrico: vivências da criança e do cuidadorfamiliar. Ribeirão Preto - SP. Dissertação [mestrado em ciências] - Universidade de São Paulo; 2013.

(39) Docherty SL, Barfield R, Thaxton C, Brandon D. A qualidade de vida de crianças que vivem com doenças crônicas ou complexas. In: Hockenberry MJ, Wilson D. Wong: Fundamentos de Enfermagem Pediátrica. Elsevier. Tradução da 9 edição; 2014. 1160-1230.

(40) Castro EHB. A experiência do câncer infantil: repercussões familiares, pessoais e sociais. Revista mal-estar e subjetividade. 2010 set; X (3): 971-994.

(41) Azevedo ND, Collet N, Leite AIT, Oliveira NRP, Oliveira BRG. Cuidado de enfermagem a famílias de crianças hospitalizadas por doença crônica. Cienc. Cui. Saude. 2012 jul-set; 11 (3): 522-528.

(42) Oliveira MR, Justa MRDE, Munguba MCS, Albuquerque LS, Diógenes MAR, Verde SMML. Rev Bras Promoç Saúde. 2015 out./dez; 28(4): 560-567.

(43) Silva MAS, Collet N, Silva KL, Moura FM. Cotidiano da família no enfrentamento da condição crônica na infância. Acta Paul Enferm. 2010; 23(3): 359-65. 
